\title{
25 Research Soure \\ Robust ferroelectricity enhancement of PZT thin films by a homogeneous seed layer
}

jie jiang ( $\sim$ jiangjie@xtu.edu.cn )

Xiangtan University School of Materials Science and Engineering

Lei Liu

Xiangtan University School of Materials Science and Engineering

Kuo Ouyang

Xiangtan University School of Materials Science and Engineering

Zhouyu Chen

Xiangtan University School of Materials Science and Engineering

Shengtao Mo

Xiangtan University School of Materials Science and Engineering

Qiangxiang Peng

Xiangtan University School of Materials Science and Engineering

Limei Jiang

Xiangtan University School of Materials Science and Engineering

\section{Zeyu Huang}

Xiangtan University School of Materials Science and Engineering

Qiong Yang

Xiangtan University School of Materials Science and Engineering

\section{Research Article}

Keywords: PZT thin films, Seed islands, Sol-gel process

Posted Date: August 2nd, 2021

DOl: https://doi.org/10.21203/rs.3.rs-763002/v1

License: (c) (1) This work is licensed under a Creative Commons Attribution 4.0 International License.

Read Full License 


\section{Abstract}

With its excellent ferroelectric properties such as large dielectric constant and large remanent polarization, PZT thin films are extensively used in micro-sensors and other devices. In this study, the solgel process was used to fabricate $\mathrm{Pb}\left(\mathrm{Zr}_{0.52} \mathrm{Ti}_{0.48}\right) \mathrm{O}_{3}$ thin films with $\mathrm{Pb}\left(\mathrm{Zr}_{x} \mathrm{Ti}_{1-\chi}\right) \mathrm{O}_{3}$ seed islands. The experimental consequences demonstrate that all the $\mathrm{Pb}\left(\mathrm{Zr}_{0.52} \mathrm{Ti}_{0.48}\right) \mathrm{O}_{3}$ thin films with $\mathrm{Pb}\left(\mathrm{Zr}_{x} \mathrm{Ti}_{1-x}\right) \mathrm{O}_{3}$ seeds show pure perovskite phase with no other impurity phases, and the electrical properties of $\mathrm{Pb}\left(\mathrm{Zr}_{0.52} \mathrm{Ti}_{0.48}\right) \mathrm{O}_{3}$ thin films modified by $\mathrm{Pb}\left(\mathrm{Zr}_{x} \mathrm{Ti}_{1-x}\right) \mathrm{O}_{3}$ seed islands with different $\mathrm{Zr} / \mathrm{Ti}$ ratios are improved, such as remanent polarization increased, dielectric properties increased, coercive electric field decreased, leakage current density decreased, etc. In particular, the electrical properties of the $\mathrm{Pb}\left(\mathrm{Zr}_{0.52} \mathrm{Ti}_{0.48}\right) \mathrm{O}_{3}$ thin films with $\mathrm{Pb}\left(\mathrm{Zr}_{x} \mathrm{Ti}_{1-x}\right) \mathrm{O}_{3}$ seed islands are the most optimal when the $x$ is 0.52 . This paper provides a new technique for optimizing the electrical properties of PZT thin films, which is of great significance for breaking through the bottleneck of the development of ferroelectric memory.

\section{Introduction}

The perovskite lead zirconate titanate $\mathrm{Pb}(\mathrm{Zr}, \mathrm{Ti}) \mathrm{O}_{3}(\mathrm{PZT})$ thin films are extensively used as micro-sensors, piezoelectric actuators, micro-electromechanical system devices, and non-volatile ferroelectric random access memories (FeRAM), because of their large dielectric constant, excellent piezoelectric effects, and large remanent polarization. Especially for FeRAMs, it has high requirements for the ferroelectric properties and fatigue resistance of ferroelectric thin films [1-6]. Unfortunately, there are still some problems that need to be solved urgently for ferroelectric thin films, such as excessive leakage current density and poor fatigue resistance, which enormously affect the performance potential and stability of devices for FeRAM. Therefore, how to improve the performance of PZT thin films to meet the development needs of a new high-performance ferroelectric memory is a problem that we need to solve now [7-9].

In the past period, a considerable amount of research was carried out towards saving the above problems. Lu et al. [10] added ethylene glycol as solvent based on the original solvent, which contributed to the formation of nuclei and improved the electrical properties of PZT films. In order to control the phase composition of the PZT film to obtain more stable ferroelectric properties, Choi et al. [11] studied the effect of the $\mathrm{O} 2$ gas ratio on the formation of the perovskite phase and conductivity of the PZT thin film by changing the $\mathrm{O} 2$ gas ratio in the sputtering gas. Sun et al. [12] fabricated Mn-doped lead zirconate titanate thin films (PMZT) and Nd-doped lead zirconate titanate thin films (PNZT) by sol-gel process respectively, and systematically research the effects of $\mathrm{Mn}$ and $\mathrm{Nb}$ doping on the domain wall mobility and oxygen vacancy concentration of PZT films to improve the ferroelectric and dielectric properties properties of PZT films,.And also, Wu et al. [13] used $\mathrm{Ba}\left(\mathrm{Mg}_{1 / 3} \mathrm{Ta}_{2 / 3}\right) \mathrm{O}_{3}$ as the buffer layer to enhance the fatigue resistance of PZT thin films. Although certain properties of the PZT films can be improved to a certain extent, due to the significant heterogeneous interface between different materials, the PZT films are enslaved to diffusion and dead layer problems, which makes the films possess obvious defects. This 
increases the leakage current density, resulting in attenuation of the other electrical properties of PZT thin films [14-16]. Therefore, we propose a new method that selects PZT material itself as seed islands to control the growth of PZT thin films. Compared with the methods used to improve the performance of PZT films in the past, the first advantage of the method proposed in this paper is that the addition of the seed islands provides nucleation points for the growth of the film. Controlling the growth of the film interface through the seed islands can reduce the activation energy of the film nucleation growth, which is conducive to the rapid growth of the films, while reducing its annealing temperature and improving the compatibility with the CMOS process. Another advantage is that since the composition of the seed islands is consistent with the film, based on the role of the seed islands, it reduces the defects and lattice mismatch caused by choosing other different materials as the seed islands to form a heterogeneous interface. The interface induction of seed islands ensures the formation of a high-quality PZT film consistent with the orientation of the seed islands during the subsequent PZT film formation process.

In this work, (111)-PZT thin films with different $\mathrm{Zr} / \mathrm{Ti}$ ratios seed islands were grown by sol-gel $[17,18]$. First of all, we added $\mathrm{Pb}\left(\mathrm{Zr}_{x} \mathrm{Ti}_{1-\chi}\right) \mathrm{O}_{3}$ seeds of different $\mathrm{Zr} / \mathrm{Ti}$ ratios to the substrates which would not change the crystalline orientation of the $\mathrm{Pb}\left(\mathrm{Zr}_{0.52} \mathrm{Ti}_{0.48}\right) \mathrm{O}_{3}$ thin films. Then we fabricated $\mathrm{Pb}\left(\mathrm{Zr}_{0.52} \mathrm{Ti}_{0.48}\right) \mathrm{O}_{3}$ thin films with the same thickness on these substrates [19]. Finally, the microstructure and electrical properties of these PZT films, such as remanent polarization, dielectric constant, leakage current density, etc., were measured by various experimental instruments [20]. By comparing the measured experimental parameters, we systematically discussed the influence of $\mathrm{Pb}\left(\mathrm{Zr}_{x} \mathrm{Ti}_{1-\chi}\right) \mathrm{O}_{3}$ seed islands on the electrical properties of $\mathrm{Pb}\left(\mathrm{Zr}_{0.52} \mathrm{Ti}_{0.48}\right) \mathrm{O}_{3}$ thin films. We found that $\mathrm{PZT}$ seed islands with different $\mathrm{Zr} / \mathrm{Ti}$ ratios can commendably adjust the microstructure of the thin films. Moreover, the electrical properties of PZT ferroelectric thin films can be effectively enhanced by the seed islands. When the $\mathrm{Zr} / \mathrm{Ti}$ ratio of seed islands was $52 / 48$, the regulation effect was the most remarkable.

\section{Experimental Section}

Here we used the sol-gel method to fabricate PZT thin films in oxygen atmosphere. Lead acetate trihydrate, zirconium acetate pentahydrate, titanium isopropoxide, acetic acid, and 2-methoxyethanol were used as the source materials and solvents. The concentration of the final solution of $\mathrm{PbZr}_{0.52} \mathrm{Ti}_{0.48} \mathrm{O}_{3}$ was adjusted to $0.2 \mathrm{~mol} / \mathrm{L}$ by adding solvents. Similarly, $0.05 \mathrm{~mol} / \mathrm{L} \mathrm{PbTiO}_{3}$,

$\mathrm{PbZr}_{0.25} \mathrm{Ti}_{0.75} \mathrm{O}_{3}, \mathrm{PbZr}_{0.52} \mathrm{Ti}_{0.48} \mathrm{O}_{3}, \mathrm{PbZr}_{0.75} \mathrm{Ti}_{0.25} \mathrm{O}_{3}$ solutions were prepared. $10 \%$ extra lead was added to compensate for the lead loss during the annealing of the film (for all the sols). The films of PZT were coated on $\mathrm{Pt} / \mathrm{Ti} / \mathrm{SiO}_{2} / \mathrm{Si}$ substrates directly, or on $\mathrm{Pt} / \mathrm{Ti} / \mathrm{SiO}_{2} / \mathrm{Si}$ substrates containing the seed islands of $\mathrm{PbTiO}_{3}, \mathrm{PbZr}_{0.25} \mathrm{Ti}_{0.75} \mathrm{O}_{3}, \mathrm{PbZr}_{0.52} \mathrm{Ti}_{0.48} \mathrm{O}_{3}, \mathrm{PbZr}_{0.75} \mathrm{Ti}_{0.25} \mathrm{O}_{3}$ annealed at $600^{\circ} \mathrm{C}$, respectively. After spinning coating, the coated films were dried at $180^{\circ} \mathrm{C}$ for 3 minutes and pyrolyzed at $400^{\circ} \mathrm{C}$ for 5 minutes. These processes were repeated four times to obtain desired film thickness. After that, the films were finally annealed at $600^{\circ} \mathrm{C}$ for 5 minutes using RTP. 
To investigate the electric properties of the films, Pt top electrodes with a diameter of $200 \mu \mathrm{m}$ were deposited on the films by DC (direct current) sputtering (ETD-3000, China). The microstructure characterization of the films was representation by X-ray diffractometer (XRD, Rigaku D/MAX-2500PC, Japan) with Cu Ka radiation, the surface morphology of the films was representations by AFM (Bruker Multimode). The dielectric properties of the films were measured using semiconductor characterization system (Agilent B1500A, USA). The ferroelectric properties were analyzed by ferroelectric test systems (Radiant Technologies Precisions workstations RT 66A, USA).

\section{Results And Discussion}

All the $\mathrm{Pb}\left(\mathrm{Zr}_{0.52} \mathrm{Ti}_{0.48}\right) \mathrm{O}_{3}$ thin films with $\mathrm{Pb}\left(\mathrm{Zr}_{x} \mathrm{Ti}_{1-\chi}\right) \mathrm{O}_{3}$ seed islands show pure perovskite phase with no other impurity phases [21], as demonstrated by the XRD patterns shown in Fig. 2a. From these X-ray diffraction patterns, we learn pure $\mathrm{Pb}\left(\mathrm{Zr}_{0.52} \mathrm{Ti}_{0.48}\right) \mathrm{O}_{3}$ thin films and the $\mathrm{Pb}\left(\mathrm{Zr}_{0.52} \mathrm{Ti}_{0.48}\right) \mathrm{O}_{3}$ thin films with $\mathrm{Pb}\left(\mathrm{Zr}_{x} \mathrm{Ti}_{1-\chi}\right) \mathrm{O}_{3}$ seed islands except for PTO prefer to performing textured (111) orientation along out of the plane with weak (110) peak [22]. The PTO is mainly textured along the (001) direction with a weak (110) peak and the crystal structure tends to be tetragonal phase since the PTO itself grown on Pt prefers to grow along (001). Although the PZT thin films modified by the seed islands grow along (100) to a small extent, there is no impurity phase. In addition, all PZT films grow in the (111) directional texture to ensure that the films own the expected crystal structure. Figure $2 b-f$ are the cross-section of SEM for PZT(52/48) ferroelectric thin films with seed islands of different $\mathrm{Zr} / \mathrm{Ti}$ ratios. All of the films we obtained are $150 \mathrm{~nm}$. It can be seen from the figures that the crystal structures of the films changed after adding the seed islands. When the PZT film has no seed islands, there are some small particles inside the film, and the size of the crystal grains is distinct. After the seed islands are added, the grain size becomes uniform, and the films become more compact. This indicates that seed islands play a certain role in promoting the crystallization of PZT films [23]. This is because the seed islands can quickly form seeds with the coincident orientation at a slightly lower temperature, which provides nucleation points for the subsequent crystallization of PZT films and decreases the activation energy of film nucleation and growth, especially the Fig. $2 e$ and $f$.

The polarization-electric field hysteresis loops $(P-E)$ and the capacitance-electric field curves $(C-E)$ on all the $\mathrm{Pb}\left(\mathrm{Zr}_{0.52} \mathrm{Ti}_{0.48}\right) \mathrm{O}_{3}$ thin films with $\mathrm{Pb}\left(\mathrm{Zr}_{x} \mathrm{Ti}_{1-\chi}\right) \mathrm{O}_{3}$ seed islands were measured at a frequency of $1 \mathrm{kHz}$ and $1 \mathrm{MHz}$ at room temperature, which are shown in Fig. 3a and c, respectively. All films exhibit ferroelectric switching loop behavior and representative "butterfly" curves $(C-E)$ which indicate excellent ferroelectric properties. Obviously, the $P$ - $E$ loops and the $C$ - $E$ curves for these PZT thin films modified by seed islands are better than the ones without seed islands, including spontaneous polarization, remnant polarization, capacitance in Fig. $3 a$ and c. The spontaneous polarization, remnant polarization, and coercive field of the films are summarized in Fig. $3 \mathrm{~b}$, and the $2 P_{\mathrm{r}}$ of these films modified by the PZT seed islands with different ratios of $\mathrm{Zr} / \mathrm{Ti}(0 / 100,25 / 75,52 / 48,75 / 25)$ are $55.9,53,56.5$ and $49.5 \mu \mathrm{C} / \mathrm{cm}^{2}$ respectively, and the remnant polarization is enhanced a lot compared with pure PZT thin film $42 \mu \mathrm{C} / \mathrm{cm}^{2}$. When the $\mathrm{Zr} / \mathrm{Ti}$ ratio of the seed islands is $52 / 48$, the regulation of the seed islands on PZT ferroelectric 
thin films reaches the maximum, while the coercive field is the smallest $\left(2 E_{\mathrm{c}}=138 \mathrm{kV} / \mathrm{cm}\right)$, and the spontaneous polarization reaches the maximum $\left(2 P_{\mathrm{S}}=161.4 \mu \mathrm{C} / \mathrm{cm}^{2}\right)$. Thus, the seed islands with the same ratio of PZT sol-gel can enhance the ferroelectric and dielectric properties of the PZT films. This is because the addition of the seed islands optimizes the thin film microstructure that is crucial to get access to high performance [24]. Furthermore, the polarization fatigues of all the $\mathrm{Pb}\left(\mathrm{Zr}_{0.52} \mathrm{Ti}_{0.48}\right) \mathrm{O}_{3}$ thin films with $\mathrm{Pb}\left(\mathrm{Zr}_{x} \mathrm{Ti}_{1-\chi}\right) \mathrm{O}_{3}$ seed islands are displayed in Fig. $3 \mathrm{~d}$. It can be seen that the seed islands have a great influence on the fatigue resistance of the the films. When the ratio of the seed islands is $52 / 48$, the thin film shows the most superior fatigue resistance, can reach $10^{9}$ cycles without attenuation, which is attributed to the high quality and stability of the film structure. The improvement of ferroelectric properties of these seed-films is since PZT seeds provide nucleation points for subsequent crystallization of PZT precursor solution, thus reducing the nucleation barrier, shown in Fig. 1. What's more, the reason why the best ferroelectric and dielectric properties appear in the ones whose ratio of $\mathrm{Zr} / \mathrm{Ti}$ get to 52/48 is due to this ratio of the seed is the same with the following covered PZT $(\mathrm{Zr} / \mathrm{Ti}=52 / 48)$ thin film, as a result, it can induce the directional crystallization of PZT film to the greatest extent, and greatly reduce the defects, strain and dead layer caused by interface mismatch, making the interface between seed islands and the thin film better than others $[25,26]$.

In order to further investigate the quality of PZT films, dielectric properties testing and leakage current density testing are essential. Figure $4 a$ is a dielectric spectrum $(\mathbb{Q}-F)$ of PZT thin films with seed islands in different $\mathrm{Zr} / \mathrm{Ti}$ ratios. As it can be seen from the figure, they were measured at room temperature with a frequency range from $1 \mathrm{kHz}$ to $1 \mathrm{MHz}$ function varies. The dielectric constants of all the $\mathrm{Pb}\left(\mathrm{Zr}_{0.52} \mathrm{Ti}_{0.48}\right) \mathrm{O}_{3}$ thin films slowly decrease linearly as the logarithm of the frequency increases. And the dielectric constants of films modified by seed islands are all higher than no modified one [27]. When the $\mathrm{Zr} / \mathrm{Ti}$ ratio of seed islands is $52 / 48$, the dielectric constant reaches the maximum, and the dielectric constant is 960 at the frequency of $1 \mathrm{kHz}$, which is about twice as high as that of pure PZT film. Adding seed islands to the interface between the bottom electrodes and the thin films can reduce the overall activation energy of the $\mathrm{PbZr}_{0.52} \mathrm{Ti}_{0.48} \mathrm{O}_{3}$ thin films for crystallization, and the interfacial crystallization is improved. At the same time, the diffusion is reduced between thin films and substrates, which decrease the deed layer, and the grain size is more uniform and the defects are less [28]. Therefore seed islands can amplify the dielectric constant $[29,30]$. Figure $4 \mathrm{~b}$ shows the leakage current densities as a function of the electric field with the Pt top electrodes for the above PZT thin films. It is obvious that the leakage current densities of PZT thin films modified by seed islands are smaller than the one without seed islands. This is because the addition of the extremely low concentration of $\mathrm{PZT}(\mathrm{Zr} / \mathrm{Ti}=52 / 48)$ as the seed islands provides nucleation points for subsequent crystallization of PZT films, which reduces the activation energy of film nucleation and growth. Besides, it can also maintain high surface energy, which is conducive to the diffusion of thin films surface at low temperature and allows the films and oxygen to be in full contact. Thus, the crystallization transition speed of the thin film is increased, the oxygen vacancy concentration in the thin film is decreased, which increases the density of the thin film and reduces the defects in the thin film. And finally, the leakage current density of the thin film is reduced, which corresponds to the experimental results of fatigue resistance in Fig. 3d [31, 32]. 
In order to characterize the mesoscopic domain switching of the thin films, piezoresponse force microscopy (PFM) is an ideal tool for both probing and switching the local ferroelectric polarization at the nanoscale. The box-in-box switched patterns were written on the five samples with the application of the electric field via a conducting tip. A tip bias of $-15 \mathrm{~V}$ was applied to pole the $12 \mu \mathrm{m} \times 12 \mu \mathrm{m}$ square region followed by another poling with a tip bias of $+15 \mathrm{~V}$ in the central area of $6 \mu \mathrm{m} \times 6 \mu \mathrm{m}$. The out-of-plane polarization signals of these five samples are shown in Fig. 5a-e, which show clear bright and dark contrast regions. As can be seen from the figures, the switching contrasts of the films with the seed islands are larger than that of the film without the seed islands. In particular, the PZT thin films with $\mathrm{Zr} / \mathrm{Ti}$ ratio of 52/48 of the seed islands can be switched when the tip voltage is $12 \mathrm{~V}$. This result suggests that adding PZT seeds into the PZT thin films can promote the domain switching. This is because the addition of PZT seed islands regulates the interface of PZT film, which reduces the internal defects of the film, and the pinning effect on the domain wall is weakened due to fewer defects, so the domain is easier to be switched [33,34]. This result can also be reflected in Fig. 3a and Fig. 4b. Figure $5 f$ shows representative local PFM phase hysteresis loops. The square loops demonstrating a $180^{\circ}$ change in the PFM phase confirm the excellent ferroelectric switching nature of these five samples. From the PFM loops, the $V_{\mathrm{c}}$ of the one modified by $\mathrm{PZT}(\mathrm{Zr} / \mathrm{Ti}=52 / 48)$ is the lowest, which also confirms the film modified by $\mathrm{PZT}(\mathrm{Zr} / \mathrm{Ti}=52 / 48)$ can accelerate the domain switch $[35,36]$ and enhance the ferroelectric properties, which is consistent with the previous macro results.

\section{Conclusions}

In conclusion, PZT thin films modified by PZT seed islands with different Zr/Ti ratios were successfully fabricated on $\mathrm{Pt} / \mathrm{Ti} / \mathrm{SiO}_{2} / \mathrm{Si}$ substrates using the sol-gel process. Compared with pure PZT films, the electrical properties of PZT films modified by PZT seed islands with different $\mathrm{Zr} / \mathrm{Ti}$ ratios, including ferroelectric properties and dielectric properties, have been improved to a large extent. Especially when the ratio of $\mathrm{Zr} / \mathrm{Ti}$ is 52/48 for the PZT seed islands, the leakage current density attain the minimum, and ferroelectric and dielectric properties are the best. Compared with other materials as the seed islands, using the same material as the seed islands can form a better interface. This work reports a new method to improve the electrical properties of ferroelectric thin films, which will promote the development of new high-performance ferroelectric memory.

\section{Declarations}

\section{Acknowledgments}

This work was supported by National Natural Science Foundation of China (Grant Nos. 11902285, 12072307), Natural Science Foundation of Hunan (Grant No. 2020JJ5526), China Postdoctoral Science Foundation (Grant No. 2019TQ0273).

\section{References}


1. Huang WH, Wang F, Yin L, Cheng RQ, Wang ZX, Sendeku MG, Wang JJ, Li NN, Yao YY, He J (2020) Gate-coupling-enabled robust hysteresis for nonvolatile memory and programmable rectifier in van der waals ferroelectric heterojunctions. Adv Mater 32:1908040

2. Nguyen MD, Houwman EP, Dekkers M, Nguyen CTQ, Vu HN, Rijnders G (2016) Research update: enhanced energy storage density and energy efficiency of epitaxial $\mathrm{Pb}_{0.9} \mathrm{La}_{0.1}\left(\mathrm{Zr}_{0.52} \mathrm{Ti}_{0.48}\right) \mathrm{O}_{3}$ relaxorferroelectric thin-films deposited on silicon by pulsed laser deposition. APL Mater 4:080701

3. Jiang J, Yang Q, Zhang Y, Li XY, Shao PW, Hsieh YH, Liu HJ, Peng QX, Zhong GK, Pan XQ, Chu YH, Zhou YC (2019) Self-assembled ferroelectric nanoarray. ACS Appl Mater Interfaces 11:2205-2210

4. Garcia V, Fusil S, Bouzehouane K, Enouz-Vedrenne S, Mathur ND, Barthélémy A, Bibes M (2009) Giant tunnel electroresistance for non-destructive readout of ferroelectric states. Nat $460(: 81-84$,

5. Liu SY, Zou D, Yu XG, Wang ZK, Yang ZB (2020) Transfer-free PZT thin films for flexible nanogenerators derived from a single-step modified sol-gel process on 2D Mica. ACS Appl Mater Interfaces 12:54991-54999

6. Chu J, Wang Y, Wang X, Hu K, Rao G, Gong C, Wu C, Hong H, Wang X, Liu K, Gao C (2021) J. Xiong, 2D polarized materials: ferromagnetic, ferrovalley, ferroelectric materials, and melated heterostructures. Adv Mater 33:2004469

7. Chun MC, Park S, Park S, Park G, Kang BS (2019) Effects of Pb content and electrode materials on the ferroelectric properties of $\mathrm{Pb}\left(\mathrm{Zr}_{0.52} \mathrm{Ti}_{0.48}\right) \mathrm{O}_{3}$ thin films. J Alloys Compd 781 (:1028-1032.)

8. Podgorny Y, Vorotilov K, Sigov A (2016) Estimation of steady-state leakage current in polycrystalline PZT thin films. AIP Adv 6 (:095025, )

9. Park HW, Roh J, Lee YB, Hwang CS (2019) Modeling of negative capacitance in ferroelectric thin films. Adv Mater 31:1805266

10. Lu G, Dong H, Chen J, Cheng J (2017) Enhanced dielectric and ferroelectric properties of PZT thin films derived by an ethylene glycol modified sol-gel method. J Sol-Gel Sci Technol 82:530-535

11. Choi S, Park J, Kang J, Johnson AC, Kang Y (2016) Surface characterization of PZT thin films obtained at various $\mathrm{O}_{2}$ gas ratios. Vacuum $128(: 234-239$, )

12. Sun $H$, Zhang Y, Liu XF, Guo SS, Liu Y, Chen $W$ (2015) The effect of Mn/Nb doping on dielectric and ferroelectric properties of PZT thin films prepared by sol-gel process. J Sol-Gel Sci Technol 74 (:378386, )

13. Wu Z, Zhou J, Chen W, Shen J, Hu L, Lv C (2015) Effects of Ba $\left(\mathrm{Mg}_{1 / 3} \mathrm{Ta}_{2 / 3}\right) \mathrm{O}_{3}$ buffer layer on the fatigue behavior in $\mathrm{Pb}\left(\mathrm{Zr}_{0.52} \mathrm{Ti}_{0.48}\right) \mathrm{O}_{3}$ thin films. J Sol-Gel Sci Technol 74:234-239

14. Yang Q, Cao JX, Zhou YC, Sun LZ, Lou XJ (2016) Dead layer effect and its elimination in ferroelectric thin film with oxide electrodes. Acta Mater 112:216-223

15. Chen Q, Yuan S, Hou ZP, Tang YL, Zhang JP, Wang T, Li K, Zhao W, Liu XJ, Chen L, Martin LW, Chen ZH (2021) Recent progress on topological structures in ferroic thin films and heterostructures. Adv Mater 33:2000857 
16. A AJ, Rangappa D, Dutta S (2019) Double doping effect on ferroelectric and leakage current behavior of $\mathrm{Pb}\left(\mathrm{Zr}_{0.52} \mathrm{Ti}_{0.48}\right) \mathrm{O}_{3}$ thin film, Ceram. Int 45 (:25027-25033. )

17. Xiao M, Li SD, Lei ZC (2015) Study of (111)-oriented PZT thin films prepared by a modified sol-gel method. J Mate Sci: Mater Electron 26 (:4031-4037, )

18. Cui Y, Gu W, Kong XX, Gao ZD, Yu SY (2019) Study of acetic acid addition on properties of PZT films prepared by sol-gel method. J Mate Sci: Mater Electron 30 (:9194-9199,. )

19. Yang JG, Chen H, Wang CH, Tao JH, Dai W, Wu T, Li J (2020) Influence of substrate thickness on the electrical properties of flexible $\mathrm{PbZr}_{0.52} \mathrm{Ti}_{0.48} \mathrm{O}_{3}$ thin films grown on Mica. J Electron Mater 49:54495454

20. Liang K, Buditama A, Chien D, Cui J, Cheung PL, Goljahi S, Tolbert SH, Chang JP, Lynch CS (2015) The conductivity mechanism and an improved $\mathrm{C}-\mathrm{V}$ model of ferroelectric PZT thin film. J Appl Phys 117:174107

21. Das D, Sanchez L, Martin J, Power B, Isaacson S, Polcawich RG, Chasiotis I (2018) Control of ferroelectric and linear piezoelectric response of PZT films through texture. J Amer Ceram Soc 101:2965-2975

22. Delimova L, Guschina E, Zaitseva N, Pavlov S, Seregin D, Vorotilov K, Sigov A (2017) Effect of seed layer with low lead content on electrical properties of PZT thin films. J Mater Res 32 (:1618-1627, )

23. Yazawa K, Uchida H, Blendell JE (2020) Origin of grain size effects on voltage-driven ferroelastic domain evolution in polycrystalline tetragonal lead zirconate titanate thin film. Adv Funct Mater 30 $(: 1909100$,

24. Lin CC, Su CW, Weng CM, Chien YC, Chu SY, Huang CH, Hong CS, Tsai CC (2018) Effects of two-stage post-annealing process on microstructure and electrical properties of sol-gel derived nonstoichiometric NKN thin films. Appl Surf Sci 428 (:199-206, )

25. Liu R, Ulbrandt JG, Hsing HC, Gura A, Bein B, Sun A, Pan C, Bertino G, Lai A, Cheng K, Doyle E, EvansLutterodt K, Headrick RL, Dawber M (2020) Role of ferroelectric polarization during growth of highly strained ferroelectric materials. Nat Commun 11:2630

26. Liu WY, Jiang J, Yang Q, Zhou YC (2019) Effect of PTO seed layer on crystallization temperature and electrical properties of PZT ferroelectric thin films. J Xiangtan Univ 41 (:22-29,. )

27. Jiang J, Bitla Y, Peng QX, Zhou YC, Chu YH (2017) Flexible ferroelectric element based on van der waals heteroepitaxy. Sci Adv 3:e1700121

28. Do MT, Gauquelin N, Nguyen MD, Wang J, Verbeeck J, Blom F, Koster G, Houwman EP, Rijnders G (2020) Interfacial dielectric layer as an origin of polarization fatigue in ferroelectric capacitors. Sci Rep 10:7310

29. Yu H, Chung C-C, Shewmon N, Ho S, Carpenter JH, Larrabee R, Sun T, Jones JL, Ade H, O'Connor BT, So $F$ (2017) Flexible inorganic ferroelectric thin films for nonvolatile memory devices. Adv Funct Mater 27:1700461 
30. Wang X, Wang FA, Qi LP, Guo R, Li B, Chen D, Zou HL (2020) Orientation transition, dielectric, and ferroelectric behaviors of sol-gel derived PZT thin films deposited on Ti-Pt alloy layers: A Ti contentdependent study. Ceram Int 46:10256-10261

31. Yang Q, Tao LL, Zhang YK, Li M, Jiang Z, Tsymbal EY, Alexandrov V (2019) Ferroelectric tunnel junctions enhanced by a polar oxide barrier layer. Nano Lett 19:7385-7393

32. Geng WP, Chen X, Pan L, Qiao XJ, He J, Mu JL, Hou XJ, Chou XJ (2021) Improved crystallization, domain, and ferroelectricity by controlling lead/oxygen vacancies in Mn-doped PZT thin films. Mater Charact 176:111131

33. Agar JC, Damodaran AR, Okatan MB, Kacher J, Gammer C, Vasudevan RK, Pandya S, Dedon LR, Mangalam RVK, Velarde GA, Jesse S, Balke N, Minor AM, Kalinin SV, Martin LW (2016) Highly mobile ferroelastic domain walls in compositionally graded ferroelectric thin films. Nat Mater 15:549-556

34. Yuan G, Huang H, Li C, Liu D, Cheng Z, Wu D (2020) Ferroelastic-domain-assisted mechanical switching of ferroelectric domains in $\mathrm{Pb}(\mathrm{Zr}, \mathrm{Ti}) \mathrm{O}_{3}$ thin films. Adv Electron Mater 6:2000300

35. Li ZH, Huang XL, Wang YC, Tang YX, Zhao XY, Wang FF, Wang T, Shi WZ, Duan ZH (2020) Ferroelectric and piezoelectric response in (100)-oriented $\mathrm{Mn}$-doped $\mathrm{Bi}_{0.5} \mathrm{Na}_{0.5} \mathrm{TiO}_{3}-\mathrm{BaTiO}_{3}$ thin films. J Mater Sci 55 (:8088-8094, )

36. Luca GD, Rossell MD, Schaab J, Viart N, Fiebig M, Trassin M (2017) Domain wall architecture in tetragonal ferroelectric thin films. Adv Mater 29 (:1605145, )

\section{Figures}

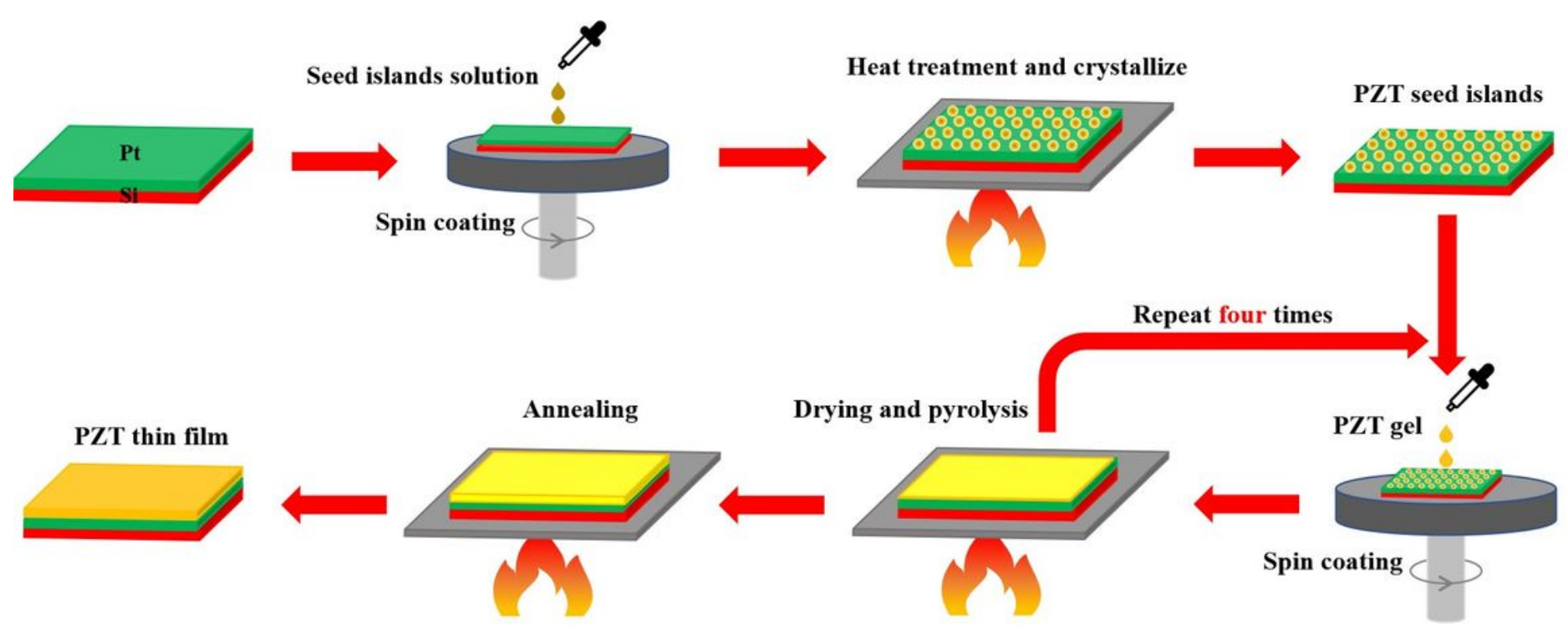

\section{Figure 1}

Crystal growth diagram of the PZT ferroelectric thin films with seed islands regulating interface. 

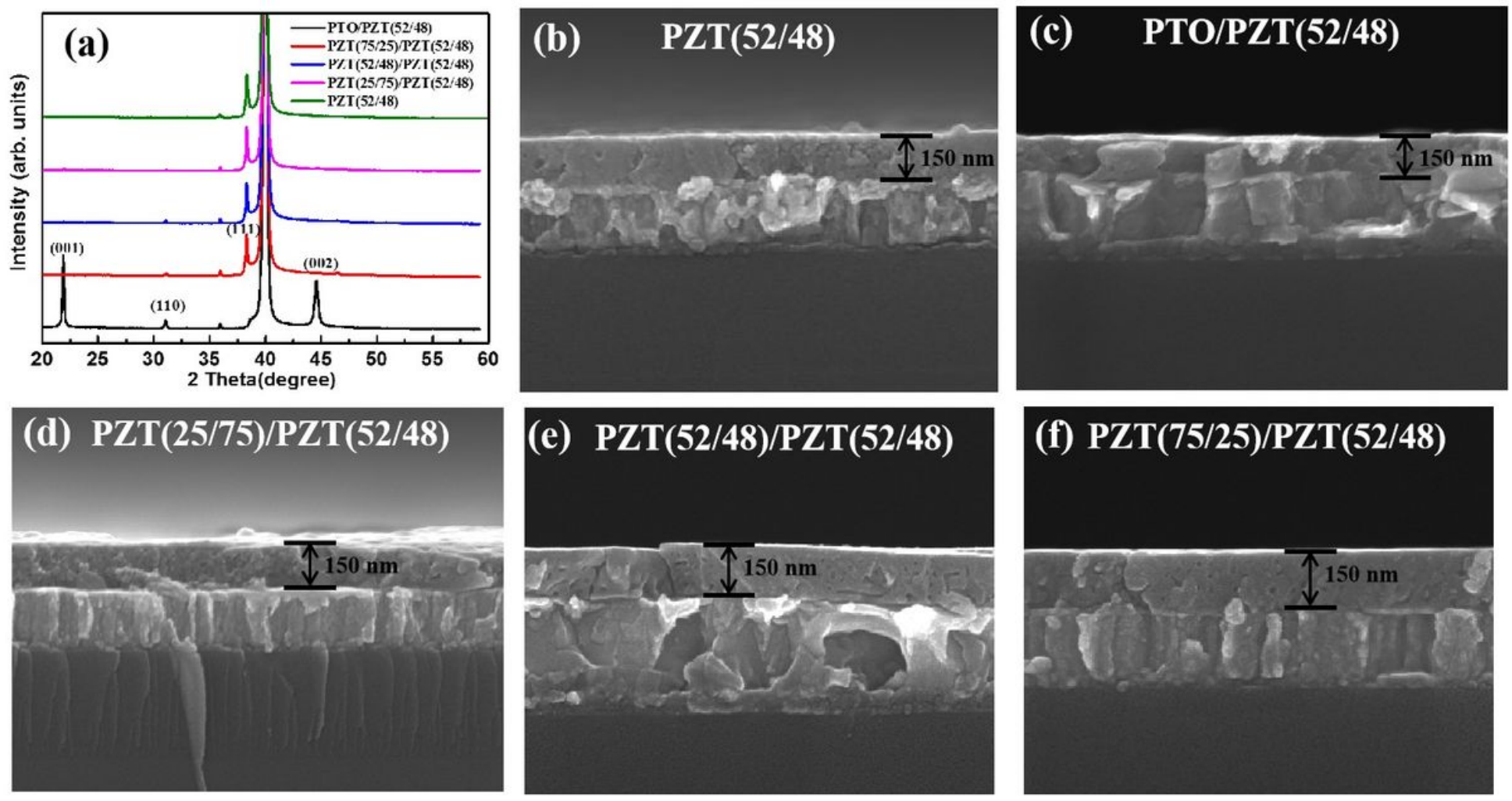

Figure 2

(a) Theta-2theta map of PZT ferroelectric thin films. Cross-section of SEM for PZT(52/48) ferroelectric thin films (b) with no seed islands, (c) with seed islands of PTO, (d) with seed islands of Zr/Ti ratio of 25/75, (e) with seed islands of $\mathrm{Zr} / \mathrm{Ti}$ ratio of 52/48, (f) with seed islands of $\mathrm{Zr} / \mathrm{Ti}$ ratio of 75/25. 

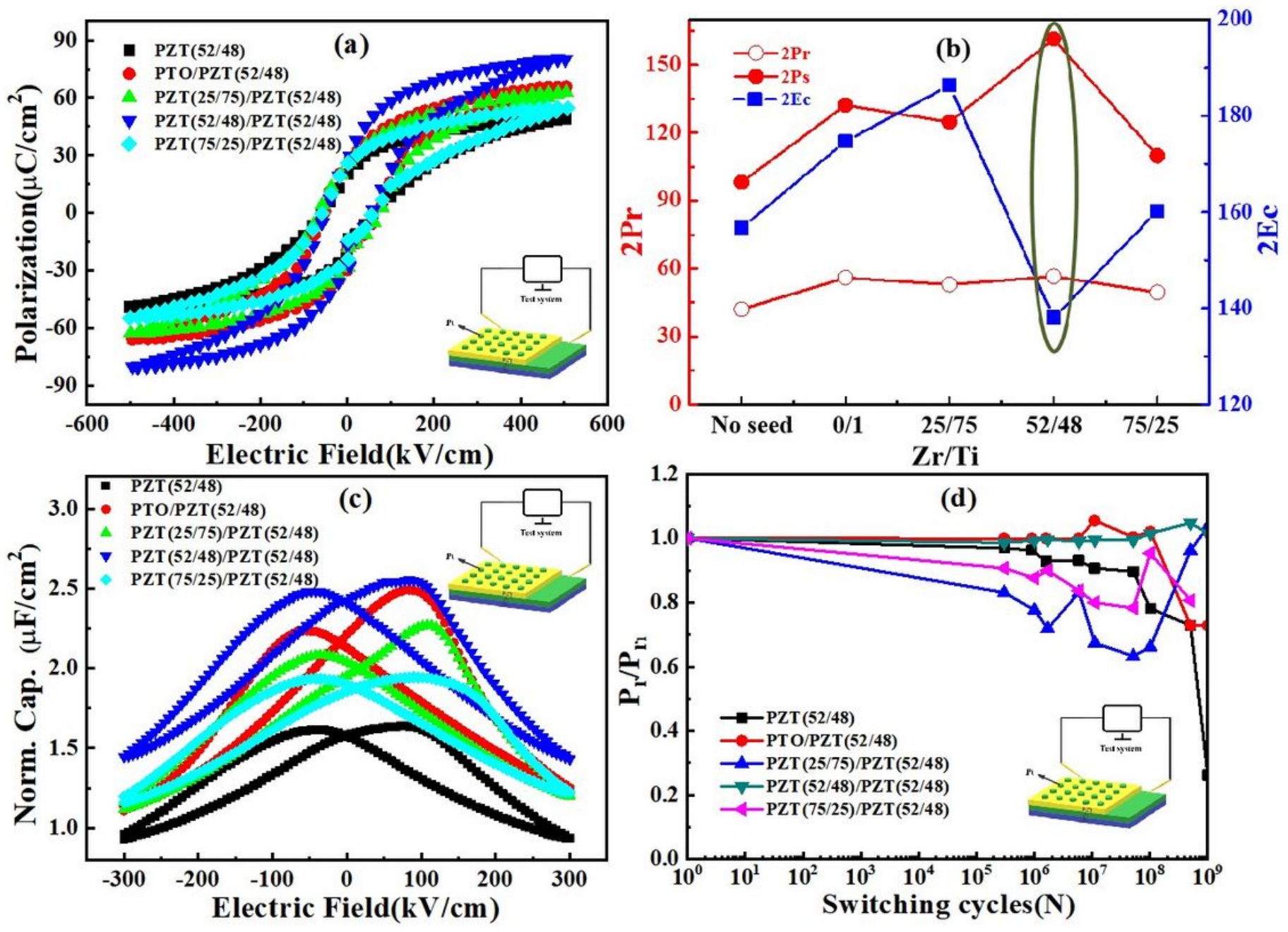

Figure 3

(a) The polarization-electric field hysteresis loops (P-E), (b) the changes of 2Pr, 2Ps, and 2Ec summarized from (a), (c) capacitance-electric field (C-E) curves and (d) fatigue resistance for PZT ferroelectric thin films. 

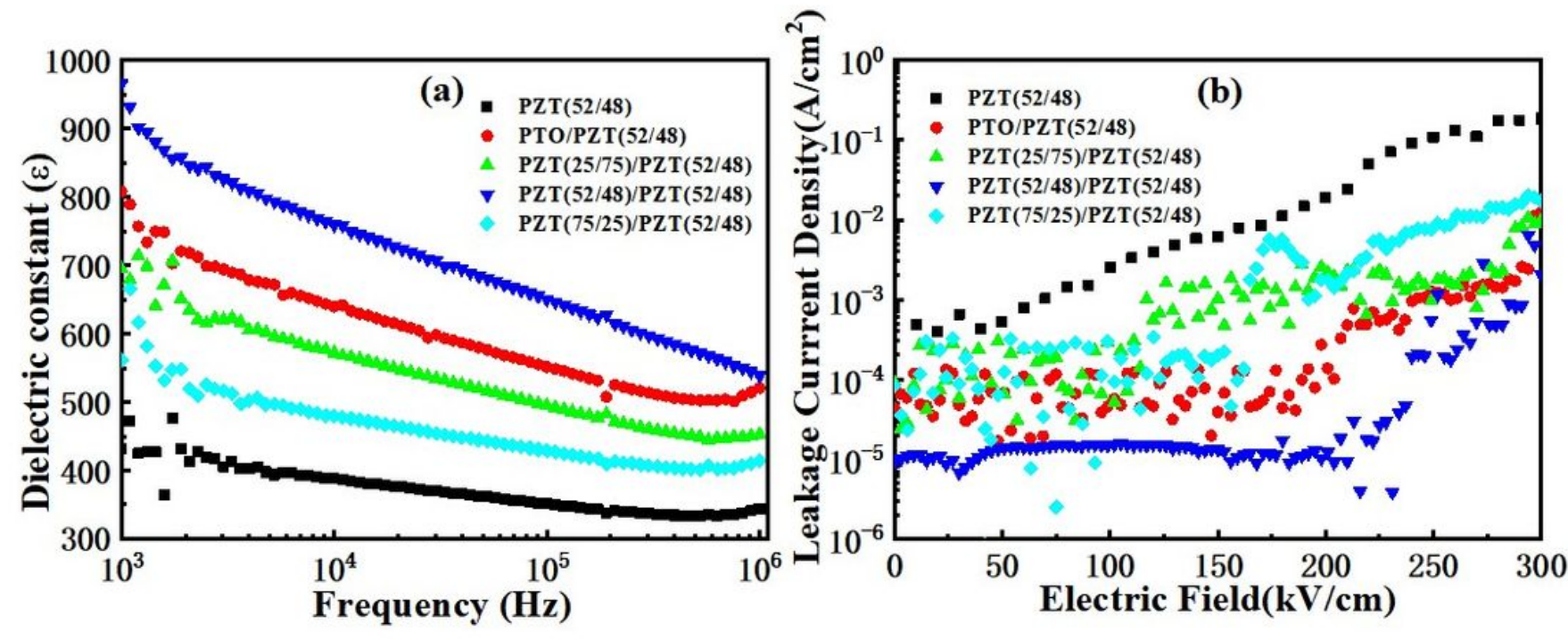

Figure 4

(a) Dielectric constant-frequency (ख-F) curves, (b) Leakage current density-electric field curves (J-E) of PZT thin films.
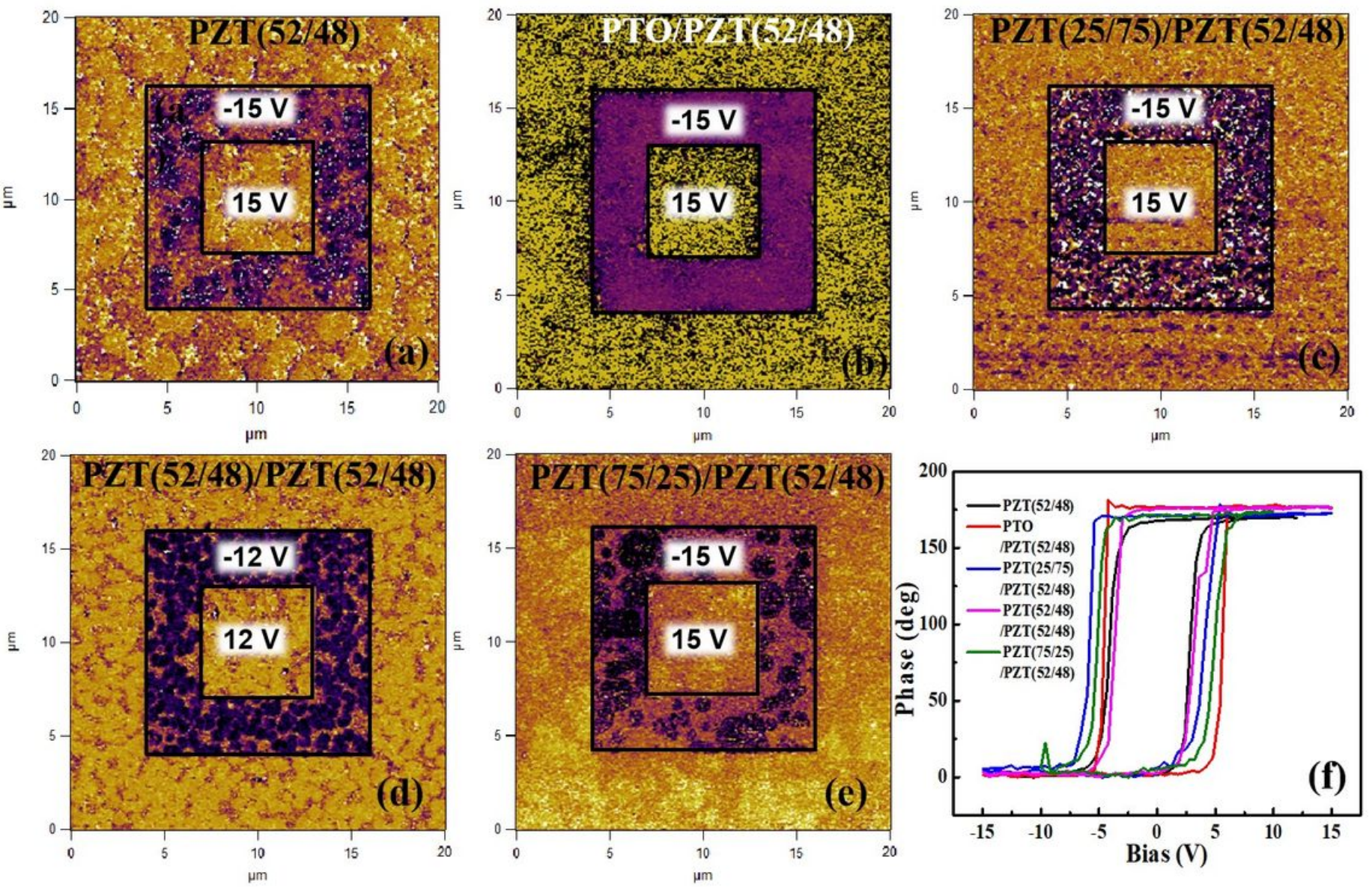

Figure 5 
PFM phase diagrams for PZT thin films (a) with no seed islands, (b) with seed islands of PTO, (c) with seed islands of $\mathrm{Zr} / \mathrm{Ti}$ ratio of $25 / 75$, (d) with seed islands of $\mathrm{Zr} / \mathrm{Ti}$ ratio of $52 / 48$, (e) with seed islands of $\mathrm{Zr} / \mathrm{Ti}$ ratio of $75 / 25$, and (f) phase-voltage curves of PZT thin films. 